\title{
Subclinical atherosclerosis in non-dialysis chronic renal patients
}

\author{
Borges Wagner Ramos ${ }^{1 *}$, Fernandes Andre Mauricio Souza ${ }^{2}$, Duraes Andre Rodrigues ${ }^{2}$, Aras Junior Roque ${ }^{3,4}$ and Lima João ${ }^{5}$ \\ ${ }^{1}$ Vascular Surgeon, Department Vascular and Endovascular Surgery, Ana Neri Hospital, Federal University of Bahia, Brazil \\ ${ }^{2}$ Cardiologist, Cardiology Service, Ana Neri Hospital, Federal University of Bahia, Brazil \\ ${ }^{3}$ Cardiologist, Chief of the Cardiology Service, Ana Neri Hospital, Federal University of Bahia, Brazil \\ ${ }^{4}$ Professor, Post Graduate Program, Medicine and Health, Faculty of Medicine of Bahia, Federal University of Bahia, Brazil \\ ${ }^{5}$ Cardiologist, Texas, USA
}

\begin{abstract}
Background: Nowadays cardiovascular diseases are the main cause of morbid-mortality. Atherosclerosis is one of the most important in this class of diseases. Goal: Identifying subclinical atherosclerosis in a population of non-dialytic patients with chronic kidney disease.

Methods: From November 2012 to December 2013, we selected 40 patients with stage 3 or 4 of CKD (cronic kidney disease) who did not need hemodialysis. CACS (coronary artery calcium score) and MTCA (miointimal thickness of carotid artery) were calculated and their mean and standard deviation, median and quartiles. To verify the association between the variables we used the Fisher exact test and the Spearman correlation $\mathrm{p}<0.05$.

Results: The distribution of the CACS was not as expected and the median increased with age groups. The CACS was null in: $50 \%$ of the sample in all patients below 45 years of age, $50 \%$ of those between $45-49$ years of age and 50-54 years of age, $53.8 \%$ in those $55-59$ years of age and $25 \%$ of those $60-65$ years of age, however $\mathrm{p}=0.102$. The median MTCA was $0.9 \mathrm{~mm}$ with interquartile range of $0.7-1.2 \mathrm{~mm}$. In percentile 75 for age and sex were: $80 \%$ of $45 \mathrm{year}$ olds, $25 \%$ of $45-49$ year olds, $66.7 \%$ of $50-54$ year olds, $69.2 \%$ of $55-59$ year olds and $50 \%$ of $60-65$ year olds, though p value was 0.602 . We found a moderate positive correlation between age and CACS ( $r=0.458 \mathrm{p}=0.03)$ and between age and MTCA weak ( $r=0.346 \mathrm{p}=0.029)$ when performed correlation of age with the values of CACS and MTCA. The correlation between MTCA and CACS was strong(r=0.807) $\mathrm{p}<0.001$.
\end{abstract}

Conclusion: Non-invasive tests in CKD non-dialytic patients can identify subclinical atherosclerosis through the CACS and MTCA. This may change the clinical management, evolution and prognosis.

\section{Introduction}

Cardiovascular diseases (CVD) are the leading cause of morbidity and mortality today. Atherosclerosis is the most important causal factor if it is taken apart and is characterized as a progressive multifactorial disease caused by both genetic and acquired factors with lipid accumulation and development of arterial fibrosis and $[1,2]$ chronic kidney disease (CKD) participates in activation of the renin-angiotensin-aldosterone hormonal system and the sympathetic nervous system, causing complex metabolic and hormonal changes that accelerate the process of atherosclerosis. Increased blood pressure and blood volume increases pre and post load, generates myocardial hypertrophy, ventricular dysfunction, and increases free radicals contributing to both, accelerating endothelial myocardial damage as renal $[3,4]$.

The risk of CVD among CKD patients is higher than in the general population with a high prevalence of coronary artery disease (40\%) and mortality is 10 to 20 times in this population, especially those who do hemodialysis, accounting for $50 \%$ of deaths in patients [5,6]. Evaluation and research for subclinical atherosclerosis by imaging methods (calcium score in coronary tomography, ultrasound or angiography) can be used for the identification and stratification of atherosclerotic risk, considering that the burden of atherosclerotic plaque correlates with the risk of coronary events, especially in CKD dialytic patients [6].

The objective of this study is to identify subclinical atherosclerosis and classify the frequency distribution of coronary calcium scores (CACS) and percentiles of myointimal thickness of the carotid artery (MTCA) in non-dialysis CKD patients.

\section{Methods}

It is a cross-sectional study in patients with non-dialysis CKD patients without cardiovascular symptoms related to ischemia in outpatients Ana Nery Hospital in Salvador, Federal University of Bahia, (ANH/

Correspondence to: Dr. Wagner Ramos Borges, Vascular Surgeon, Department Vascular and Endovascular Surgery, Ana Neri Hospital, Federal University of Bahia, Brazil, Tel: + 55719206 8592; E-mail: wagner2076@bol.com.br

Key words: calcium score, carotid thickness, atherosclerosis

Received: December 18, 2014; Accepted: January 05, 2015; Published: January 10,2015 
BFU), Brazil. All patients underwent coronary angiotomography. The definition of chronic kidney disease staging come from the guidelines proposed by the "Kidney Disease Outcome Quality Initiative" (KDOQI) and updated by the "National Collaborating Centre for Chronic Condition" [7]. Excluded subjects were: age greater than 65 years, previous diagnosis of coronary artery disease (CAD) undergoing coronary angiography, previous percutaneous coronary intervention or coronary artery bypass grafting, as well as those who already had an established diagnosis of obstruction or carotid atherosclerotic plaque.

CT scans were performed in 128 channel multislice appliance brand Optima 600 General Electric acquisition that allows adjustment of the dose of irradiation software. Axial slices of the heart were obtained with a thickness of $3 \mathrm{~mm}$, in late diastole triggered by electrocardiogram, during the inspiratory pause time interval of $100 \mathrm{~ms}$. The image of two contiguous pixels with attenuation coefficient $>130$ Hounsfield units (HU) was considered coronary artery calcification (CC). The Agatston method for calculating the CACS was used, multiplying the calcification area in square millimeters by a factor 1,2,3 or 4 depending on the attenuation coefficients determined by calcium (factor 1: the coefficient between 130 and $199 \mathrm{Hu}, 2$ between 200 and $299 \mathrm{Hu}, 3$ when between 300 and $399 \mathrm{Hu}$ and the factor 4 higher coefficients for the $400 \mathrm{Hu}$ ). The total value of the CACS was obtained by summing all the scores of all coronary arteries obtained from CT slices. When there was no identifiable calcium CACS was considered zero. CACS 1 to 10 were classified as minimal calcification, 11-100 little, moderate when 101 to 400 and $>400$ significant calcification. To investigate gender differences an analysis of CACS on age groups were held in men and women : $<45$ years, 45-49 years 50-54 years 55-59 years 60-65 years. Calcification was also set in groups of percentiles for age and sex $[8,9]$.

The evaluation of MTCA was performed using ultrasound device General Electric Nemio 5, linear transducer 7-12 MHz, in longitudinal section, the mode $\mathrm{B}$. The measurement was performed manually in the distal common carotid (1-2 cm proximal to the carotid bifurcation) in the anterior or posterior wall of the artery, the distance between two lines represented by the echogenic lumen-intima and media-adventitia interface. Benchmark $>0.8 \mathrm{~mm}$ indicating early thickening. The table of values of the MTCA "Atherosclerosis Risk in Communities Study" was used as reference. MTCA (median value) was analyzed according to sex and age groups and expressed in percentis [10]. Descriptive statistics were performed in order to show the general and specific characteristics of the sample by calculating the mean and standard deviation, median and quartiles. To verify the link between nominal variables we use the Fisher exact test and to identify correlation between quantitative variables we used the Spearman correlation. It was considered significant when $\mathrm{p}<0.05$. The analysis was performed using the Statistical Package for Social Science (SPSS Inc., Chicago, IL, USA, Release 16.0.2, 2008). This study was approved by the Ethics Committee in Research of ANH/BFU under the number 08029912.9.0000.0045.

\section{Results}

From November 2012 to December 2013, 180 patients with CKD Clinic of Nephrology of the ANH/BFU were evaluated. Of these, we selected 40 patients with stage 3 or 4 without hemodialysis who accepted to join the study by signing the consent form before the interview and investigation exams. The clinical characteristics are shown in Table 1. Mean age was $54.6 \pm 8.94$ years, $85 \%$ were hypertensive, $50 \%$ diabetic, $22.5 \%$ smokers, $35 \%$ dyslipidemia, and $70 \%$ were nonwhite. The mean duration of chronic kidney disease diagnosed, in months, was $24.48 \pm$ 16.11 and the mean serum creatinin $(\mathrm{mg} / \mathrm{dl})$, was $2.83 \pm 1.43$.
Table 1. Clinical and laboratory characteristics in 40 patients with non-dialysis CKD evaluated by the CACS and MTCA.

\begin{tabular}{|l|c|c|c|}
\hline Variables & & $\mathbf{n}$ & $\mathbf{( \% )}$ \\
\hline Sex & Male & 9 & $(47.5 \%)$ \\
\hline Race & Female & 21 & $(52.5 \%)$ \\
\hline & & & $(70 \%)$ \\
\hline Hypertension* & (not white) & 28 & $(85 \%)$ \\
\hline Diabetes mellitus $^{* * *}$ & & 34 & $(50 \%)$ \\
\hline Smoking*** $^{* * *}$ & & 20 & $(22.5 \%)$ \\
\hline Dyslipidemia**** & & 09 & $(35 \%)$ \\
\hline Average age (years) & & 14 & \\
\hline Median MTCA (mm) & & $0.9(\mathrm{q} 1=0.7 \mathrm{q} 3=1.2)$ & \\
\hline
\end{tabular}

"As VI Brazilian Guidelines on Hypertension of the Brazilian Society of Cardiology; "**Patients with prior diagnosis and treatment; ${ }^{* * *}$ Smoking: Patients active smokers at the time of the survey. All other denied smoking even passively; ${ }^{* * * *}$ As V Brazilian Guidelines on Dyslipidemia and Prevention of Atherosclerosis Society

Table 2. Agatston coronary artery calcification in 40 non-dialytic patients with CKD according to age.

\begin{tabular}{|l|c|c|c|}
\hline Age group (years) & $\mathbf{N}(\%)$ & Median & $\begin{array}{c}\text { Interquartile range } \\
\text { (q1-q3) }\end{array}$ \\
\hline$<45$ & $05(12.5 \%)$ & - & - \\
\hline 45 a 49 & $04(10 \%)$ & 15.5 & $0-1402.75$ \\
\hline 50 a 54 & $06(15 \%)$ & 49.5 & $0-1649$ \\
\hline 55 a 59 & $13(32.5 \%)$ & 109.0 & $0-2378$ \\
\hline 60 a 65 & $12(30 \%)$ & 1929.5 & $75-2846.8$ \\
\hline
\end{tabular}

The distribution was not as expected and CACS increased together with the median age groups (Table 2). The CACS was null in $50 \%$ of the samples: in all patients below 45 years of age, $50 \%$ of those aged between 45-49 years and 50-54 years, 53.8\% for those aged between 55-59 years and 25\% for those between the ages of 60-65 years (Table 3), but $\mathrm{p}=0.102$ (not statistically significant). The median MTCA was $0.9 \mathrm{~mm}$ with range q1-q3 $0.7-1.2 \mathrm{~mm}$. Were in the 75th percentile for age and sex: $80 \%$ of 45 year olds, $25 \%$ of $45-49$ years old, $66.7 \%$ of $50-54$ year old, $69.2 \%$ of $55-59$ year old and $50 \%$ of 60 65 year old, but p value was 0.602 (not statistically significant Table 4). However when we performed the correlation of age with the values of CACS and MTCA there was a moderate positive correlation between age and CACS $(r=0.458 \mathrm{p}=0.03)$ and between age and MTCA $(r=0.346$; $\mathrm{p}=0.029$ ). The correlation between MTCA and CACS was strong $(\mathrm{r}=0.807 ; \mathrm{p}<0.001)$ (Table 5 and 6$)$.

\section{Discussion}

CKD is characterized by atherogenic cardiovascular risk factors acting together in the production of vascular lesions leading to the stage of final kidney disease and causing cardiovascular and cerebral disease $[3,4]$. We found in this study, high frequency of subclinical atherosclerosis in non-dialytic CKD patients through the evaluation of MTCA and CACS. Cardiovascular risk factors were prevalent and may have contributed to these findings, particularly in the age group above 45 years, where there was a predominance patient with hypertension and diabetes.

The MTCA is a safe, low cost and easy accessibility, identifying patients with subclinical atherosclerotic or obstructive arterial disease. Groot et al. [11] showed that up to $0.8 \mathrm{~mm}$ thick myointimal would be considered normal and above this is early arterial thickening. In our population of non-dialysis CKD found a high prevalence of 
Table 3. Distribution by age of the in the sample of patients with CKD.

\begin{tabular}{|c|c|c|c|c|c|c|c|c|c|c|}
\hline & \multicolumn{10}{|c|}{ Range of calcification as age and sex* } \\
\hline & \multicolumn{2}{|c|}{ Unidentifiable calcification } & \multicolumn{2}{|c|}{ Minimum calcification } & \multicolumn{2}{|c|}{ Little calcification } & \multicolumn{2}{|c|}{ Moderade calfification } & \multicolumn{2}{|c|}{ Important calcification } \\
\hline & $\mathbf{n}$ & $\%$ & $\mathbf{n}$ & $\%$ & $\mathbf{n}$ & $\%$ & $\mathbf{n}$ & $\%$ & $\mathbf{n}$ & $\%$ \\
\hline \multicolumn{11}{|c|}{ Age (years) } \\
\hline$<45$ & 5 & 100.0 & - & - & - & - & - & - & - & - \\
\hline $45-49$ & 2 & 50.0 & - & - & 1 & 25.0 & - & - & 1 & 25.0 \\
\hline $50-54$ & 3 & 50.0 & - & - & 1 & 16.7 & - & - & 2 & 33.3 \\
\hline $55-59$ & 7 & 53.8 & - & - & - & - & - & - & 6 & 46.2 \\
\hline $60-65$ & 3 & 25.0 & - & - & - & - & 2 & 16.7 & 7 & 58.3 \\
\hline
\end{tabular}

*As table to reference the attached calcium. Used Fisher's exact test; $\mathrm{p}$-value $=0.102$

Table 4. Percentile distribution of in 40 CKD patients classified by age groups.

\begin{tabular}{|c|c|c|c|c|c|c|}
\hline & \multicolumn{6}{|c|}{$\begin{array}{l}\text { Tracks percentile according to age and sex to myointimal thickness of } \\
\text { carotid }^{\star 2}\end{array}$} \\
\hline & \multicolumn{2}{|c|}{ P25 } & \multicolumn{2}{|c|}{ P50 } & \multicolumn{2}{|c|}{ P75 } \\
\hline & $\mathrm{n}$ & $\%$ & n & $\%$ & $\mathbf{n}$ & $\%$ \\
\hline \multicolumn{7}{|l|}{ Age (years) } \\
\hline$<45$ & 1 & 20.0 & - & - & 4 & 80.0 \\
\hline 45 a 49 & 2 & 50.0 & 1 & 25.0 & 1 & 25.0 \\
\hline 50 a 54 & 1 & 16.7 & 1 & 16.7 & 4 & 66.7 \\
\hline 55 a 59 & 1 & 7.7 & 3 & 23.1 & 9 & 69.2 \\
\hline 60 a 65 & 2 & 16.7 & 4 & 33.3 & 6 & 50.0 \\
\hline
\end{tabular}

*As reference table "Atherosclerosis Risk in Communities Study". Used Fisher's exact test; p-value $=0.602$

Table 5. Correlation Age and CACS and Age x MTCA.

\begin{tabular}{|c|c|c|}
\hline \multirow{2}{*}{ Variables } & \multicolumn{2}{|c|}{ Age } \\
\cline { 2 - 3 } & Correlation coefficient & p-valor \\
\hline CACS & 0.458 & 0.030 \\
\hline MTCA & 0.346 & 0.029 \\
\hline
\end{tabular}

Table 6. Correlation MTCA x CACS.

\begin{tabular}{|c|c|c|}
\hline \multirow{2}{*}{ Variable } & \multicolumn{2}{|c|}{ MTCA } \\
\cline { 2 - 3 } & Correlation coefficient & p-valor \\
\hline CACS & 0.807 & $<0.001$ \\
\hline
\end{tabular}

myointimal thickening in the different age groups showing an active process of subclinical atherosclerosis. However, the lack of a standard reference table for the population, especially patients with CKD and a low number of participants have contributed with the statistical not significant result.

The risk of coronary events in asymptomatic patients can be assessed by prognostic scores such as Framingham risk or reclassifying individually by non-invasive techniques to determine changes in the arterial wall as coronary calcium measured, MTCA and investigation of endothelial dysfunction, improving the identification of the patients at low and intermediate cardiovascular risk [12-15]. Studies such as the Multi-Ethnic of Atherosclerosis (MESA) and The Heinz Nixdorf Recall showed that risk stratification can be improved when adding CACS to traditional risk factors as defined by the score of Framingham $[16,17]$. Whereas patients with chronic kidney diseases are at high risk of cardiovascular events and that CACS is an independent predictor of cardiovascular risk and reclassifies individuals, it is possible that the CACS in patients with CKD be useful in risk stratification for cardiovascular events [18-22].
The age, sex and ethnicity are important factors that influence the CACS and the MTCA. Although we had the participation of many age groups and almost equal by sex, even with a small sample size, $70 \%$ of the population was considered as black. Our results indicate that in the 40 selected patients, 16 had significant calcification and intimal thickening at different ages. Some studies show that the best specificity to detect the risk of coronary events is in the evaluation of CC ranges between 35-55 years or with 60 years [23].

$50 \%$ of the patients were diabetic and these are categorized as equivalent than those with coronary disease at high risk for most current classifications risks factors of the society. Raggi et al. [24] comparing type 2 diabetic and nondiabetic patients with a null calcium score, reported that both had the same survival. Despite the CACS shows its importance in risk stratification for coronary events in the general population, further prospective studies are needed to define its prognostic significance in diabetics.

\section{Conclusion}

The use of non-invasive tests in non-dialytic CKD patients can identify subclinical atherosclerosis through the CACS and MTCA. However, more studies are needed with larger samples to determine whether there is interference in the clinical management, disease evolution and prognosis.

\section{References}

1. Libby $P$ (2002) Inflammation in atherosclerosis. Nature 420-421. [Crossref].

2. Lusis AJ (2000) Atherosclerosis. Nature 407. [Crossref].

3. Cheung AK, Sarnak MJ, Yan G, Dwyer JT, Heyka RJ, et al. (2000) Atherosclerotic cardiovascular disease risks in chronic hemodialysis patients. Kidney Int 58: 353-362. [Crossref].

4. Schiffrin EL, Lipman ML, Mann JFE (2007) Chronic Kidney Disease: Effects on the Cardiovascular System. Circulation 116: 85-97. [Crossref]

5. Foley RN, Parfrey OS, Sarnak MJ (1998) Epidemiology of cardiovascular disease in chronic renal disease. J Am Soc Nefrol 9: S16-S23 [Crossref]

6. Grundy S, Pasternak R, Greenland P, Smith S, Valentine F (1999) Assessment of cardiovascular risk by use of multiple-risk-factor assessment equations. Circulation 100: 1481-1492.

7. The National Collaborating Centre for Chronic Conditions (UK) (2008) Chronic Kidney Disease: National Clinical Guideline for Early Identification and Management in Adults in Primary and Secondary Care. [Crossref]

8. Agatston AS, Janowitz WR, Hildner F (1990) Quantification of coronary artery calcium using ultrafast computed tomography. J Am Coll Cardiol 15: 827-832. [Crossref]

9. Hoff JA (2001) Age and gender distributions of coronary artery calcium detected by electron beam tomography in 35,246 adults. Am J Cardiol 87: 1335-1339. [Crossref] 
10. Pignoli P, Tremoli E, Poli A (1986) Intimal plus medial thickness of the wall: a directed measurement with ultrasound imaging. Circulation 74: 1399-1406. [Crossref]

11. Groot E, Honing GK, Wiegman A (2004) Measurement of arterial wall thickness as a surrogate mártir for atherosclerosis. Circulation 109: III33-III38. [Crossref]

12. Sinha AK, Eigenbrodt M, Mehta JL (2002) Does carotid intima thickness indicate coronary atherosclerosis? Curr Opin Cardiol 17: 526-530. [Crossref]

13. Grobbee DE, Bots ML (1994) Carotid artery intima-media thickness as an indicator of generalized atherosclerosis? J Int Med 236: 567-573. [Crossref]

14. Santos, RD, Giannini SD, Fonseca FAH (2001) III Diretrizes Brasileiras sobre Dislipidemias e Prevenção da Aterosclerose do Departamento de Aterosclerose da Sociedade Brasileira de Cardiologia. Arq Bras Cardiol: 1-48.

15. Greenland P, Smith SC, Grundy SM (2001) Improving coronary heart disease assessment in asymptomatic people: role of traditional risk factors and non-invasive cardiovascular tests. Circulation 104: 1863-1867. [Crossref]

16. Pletcher MJ, Tice JA, Pignone M (2004) Using the coronary artery calcium score to predict coronary heart disease events: a systematic review and meta-analysis. Arch Intern Med 164: 1285-1292. [Crossref]

17. O'Rourke RA, Brundage BH, Froelicher VF, Greenland P, Grundy SM, et al. (2000) American College of Cardiology/American Heart Association Expert Consensus
Document on Electron Beam Computed Tomography for the Diagnosis and Prognosis of Coronary Artery Disease. Circulation 102: 126-140. [Crossref]

18. Polonsky TS, McClelland RL, Jorgensen NW, Bild DE, Burke GL, et al. (2010) Coronary Artery Calcium and Risk Classification for Coronary Heart Disease Predicton. JAMA 303: 1610-1616. [Crossref]

19. Hoff JA, Chomka EV, Krainik AJ (2001) Age and gender distributions of coronary artery calcium detected by electron beam tomography in 35.246 adults. Am J. Cardiol 87: 1335-1339.

20. Detrano R, Guerci AD, Carr JJ, Bild DE, Burke G, et al. (2008) Coronary Calcium as a Predictor of Coronary Events in Four Racial or Ethnic Groups. $N$ Engl J Med 358: 1336-1345. [Crossref]

21. Shah PK (2010) Screening asymptomatic subjects for subclinical atherosclerosis: can we, does it matter, and should we? J Am Coll Cardiol 56: 98-105. [Crossref]

22. Robert B (2009) Should Coronary Calcium Screening Be Use in Cardiovascular Prevention Strategies. N Engl J Med 361: 990-997.

23. Raggi $\mathrm{P}$ (2001) Coronary calcium on electron beam tomography imaging as a surrogate marker of coronary artery disease. Am J Cardiol 87: 27A-34A. [Crossref]

24. Raggi P, Shaw Berman DS, Callister TQ (2004) Prognostic value of coronary artery calcium screening in subjects with and without diabetes. $J$ Am Coll Cardiol 43: 1663 1669. [Crossref]

Copyright: ( 2015 Ramos BW. This is an open-access article distributed under the terms of the Creative Commons Attribution License, which permits unrestricted use, distribution, and reproduction in any medium, provided the original author and source are credited. 